American Journal of Applied Sciences 9 (4): 563-569, 2012

ISSN 1546-9239

(C) 2012 Science Publications

\title{
Effect of Mosquito Repellent on the Transmission Model of Chikungunya Fever
}

\author{
${ }^{1}$ Surapol Naowarat, ${ }^{1}$ Prasit Thongjaem and ${ }^{2}$ I. Ming Tang \\ ${ }^{1}$ Department of Mathematics, Faculty of Science and Technology, \\ Suratthani Rajabhat University, Surat Thani, 84100, Thailand \\ ${ }^{2}$ Department of Physics, Faculty of Science, \\ Mahidol University, Bangkok, 10400, Thailand
}

\begin{abstract}
Problem statement: In 2008 there was a large outbreak of Chikungunya fever in southern Thailand. Chikungunya fever is an emerging disease which tends to affect rubber plantation and fruit orchard workers more than other occupation. This study we considers the efficacy of using mosquito repellent as a way to prevent and control the spread of Chikungunya fever. The mathematical model of the dynamic of this disease is proposed and analyzed. Approach: A standard dynamical modeling method was applied for analysis the dynamical model. The stability of the model was determined by using Routh-Hurwitz criteria. Results: The conditions for disease free and endemic state are found. To determine the basic reproductive number $\left(R_{0}\right)$ which is the threshold parameter, if $R_{0}<1$, the disease free equilibrium point is locally asymptotically stable. If $\mathrm{R}_{0}>1$, there exist the endemic equilibrium state, which is locally asymptotically stable. Conclusion: It was found that the use of mosquito repellent significantly reduce transmission and infection of this disease which it may be an alternative intervention for communities to prevent and control the disease.
\end{abstract}

Key words: Mathematical model, chikungunya fever, basic reproductive number, equilibrium point, stability analysis, mosquito repellent

\section{INTRODUCTION}

Chikungunya fever is an arthropod-borne viral disease caused by an alphavirus of Togavivirus family, which was isolated in 1953 in Tanzania (Pioloux et al., 2007). The name, Chikungunya, originates from the Monkonde dialec of Tanzania and refers to the patient's contorted posture as a result of severe joint paints (Tilston et al., 2009). The symptoms of Chikungunya include sudden onset of fever, chills, headache, nausea, vomiting, joints paints with and without swelling, low back pain, an rash. These symptoms are very similar to those of dengue fever; there is no hemorrahagic or shock syndrome form (Massad et al., 2008). In the major outbreak of this disease in 2005 on the island of Reunion, 244,000 out of a population of 775,000 inhabitants reported that they had experienced these symptoms (Moulay et al., 2011). Chikungunya virus (CHIKV) is transmitted to humans by Aedes mosquitoes, widespread in some tropical regions. Ae. albopictus is highly competent for CHIKV (Poletti et $a l ., 2011)$. There have been many explanation that for the occurrence of large-scale Chikungunya epidemics. New strains of virus are particularly infectious to $A e$. albopictus, thereby increasing the vector competence of this species. However, vector competence consists of a variety of factors including vector life span, preference for biting human more than non-human hosts, infectiousness when infected, population density and transovarial transmission(Tsetsarkin et al., 2007). With the ongoing outbreak in Thailand, a new strain of the CHIKV was isolated in both mosquito serotypes (Thavara et al., 2009). Studies have shown that Ae. albopictus is more susceptible to the virus and therefore a more effective transmitter. The virus was found in both sexes of those two species of the mosquitoes, indicating a possible role for transovarial transmission of virus. Mathematical models have become the important tools for understanding the spread and control of disease. In this study, we are interested in the role of applying mosquito repellent on the dynamical of disease and how the efficacy of mosquito repellent relates to prevent and control the spread of disease.

\section{MATERIALS AND METHODS}

Model formulation: In our model, we assume that human population and mosquito population are constant denoted by $\mathrm{N}_{\mathrm{h}}$ and $\mathrm{N}_{\mathrm{m}}$, respectively.

Corresponding Author: Surapol Naowarat, Department of Mathematics, Faculty of Science and Technology,

Suratthani Rajabhat University, Surat Thani, 84100, Thailand 
Am. J. Applied Sci., 9 (4): 563-569, 2012

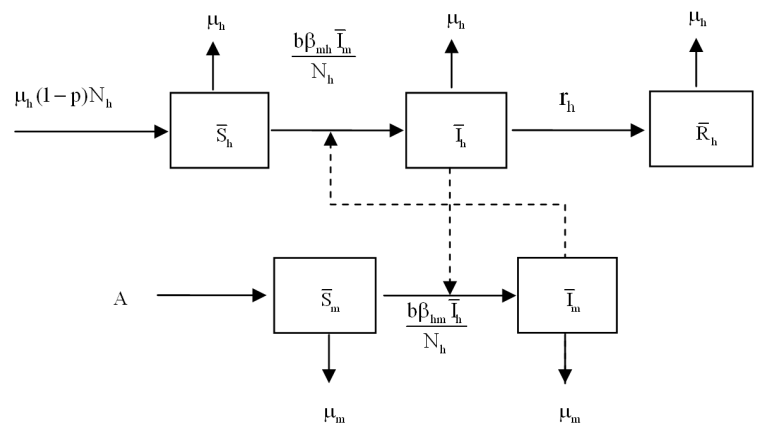

Fig. 1:Flow chart for the transmission of Chikungunya fever

The dynamics of the disease is depicted in the compartment diagram, Fig. 1.

The human population is divided into the susceptible human $\left(\overline{\mathrm{S}}_{\mathrm{h}}\right)$, the infected human $\left(\overline{\mathrm{I}}_{\mathrm{h}}\right)$ and the recover human population $\left(\overline{\mathrm{R}}_{\mathrm{h}}\right)$ compartment. The mosquito population is divided into two compartments, the susceptible mosquito $\left(\overline{\mathrm{S}}_{\mathrm{m}}\right)$, the infected mosquito $\left(\overline{\mathbf{I}}_{\mathrm{m}}\right)$, the recovered mosquito does not exist, since the mosquito infected for over all their life.

The transmission dynamics of the chikungunya fever are described by the following ordinary differential equations Eq. 1a and 1b:

$\frac{\mathrm{d} \overline{\mathrm{S}}_{\mathrm{h}}}{\mathrm{dt}}=\mu_{\mathrm{h}}(1-\mathrm{p}) \mathrm{N}_{\mathrm{h}}-\left(\frac{\mathrm{b} \beta_{\mathrm{mh}} \overline{\mathrm{S}}_{\mathrm{h}} \overline{\mathrm{I}}_{\mathrm{m}}}{\mathrm{N}_{\mathrm{h}}}\right)-\mu_{\mathrm{h}} \overline{\mathrm{S}}_{\mathrm{h}}$

$\frac{\mathrm{d} \overline{\mathrm{I}}_{\mathrm{h}}}{\mathrm{dt}}=\left(\frac{\mathrm{b} \beta_{\mathrm{mh}} \overline{\mathrm{S}}_{\mathrm{h}} \overline{\mathrm{I}}_{\mathrm{m}}}{\mathrm{N}_{\mathrm{h}}}\right)-\left(\mathrm{r}_{\mathrm{h}}+\mu_{\mathrm{h}}\right) \overline{\mathrm{I}}_{\mathrm{h}}$

$\frac{d \overline{\mathrm{R}}_{\mathrm{h}}}{\mathrm{dt}}=\mathrm{r}_{\mathrm{h}} \overline{\mathrm{I}}_{\mathrm{h}}-\mu_{\mathrm{h}} \overline{\mathrm{R}}_{\mathrm{h}}$

$\frac{\mathrm{d} \overline{\mathrm{S}}_{\mathrm{m}}}{\mathrm{dt}}=\mathrm{A}-\left(\frac{\mathrm{b} \beta_{\mathrm{hm}} \overline{\mathrm{S}}_{\mathrm{m}} \overline{\mathrm{I}}_{\mathrm{h}}}{\mathrm{N}_{\mathrm{h}}}\right)-\mu_{\mathrm{m}} \overline{\mathrm{S}}_{\mathrm{m}}$

$\frac{\mathrm{d} \overline{\mathrm{I}}_{\mathrm{m}}}{\mathrm{dt}}=\frac{\mathrm{b} \beta_{\mathrm{hm}} \overline{\mathrm{S}}_{\mathrm{m}} \overline{\mathrm{I}}_{\mathrm{h}}}{\mathrm{N}_{\mathrm{h}}}-\mu_{\mathrm{m}} \overline{\mathrm{I}}_{\mathrm{m}}$

The Eq. $1 \mathrm{c}$ and $1 \mathrm{~d}$ can be canceled since the human and mosquito population are constant. i.e., $\overline{\mathrm{R}}_{\mathrm{h}}=\mathrm{N}_{\mathrm{h}}-\overline{\mathrm{S}}_{\mathrm{h}}-\overline{\mathrm{I}}_{\mathrm{h}}$ and $\overline{\mathrm{S}}_{\mathrm{m}}=\mathrm{N}_{\mathrm{m}}-\overline{\mathrm{I}}_{\mathrm{m}}$. By doing this we get three dependent variables, which we pick to be $S_{h}, I_{h}, I_{m}$

To analyze the model by normalizing the Eq. $1 \mathrm{a}$, $1 \mathrm{~b}, 1 \mathrm{e}$ and defining new variables Eq. 2 :
$\mathrm{S}_{\mathrm{h}}=\frac{\overline{\mathrm{S}}_{\mathrm{h}}}{\mathrm{N}_{\mathrm{h}}}, \mathrm{I}_{\mathrm{h}}=\frac{\overline{\mathrm{I}}_{\mathrm{h}}}{\mathrm{N}_{\mathrm{h}}}, \mathrm{R}_{\mathrm{h}}=\frac{\overline{\mathrm{R}}_{\mathrm{h}}}{\mathrm{N}_{\mathrm{h}}}$

$\mathrm{S}_{\mathrm{m}}=\frac{\overline{\mathrm{S}}_{\mathrm{m}}}{\mathrm{N}_{\mathrm{m}}}=\frac{\overline{\mathrm{S}}_{\mathrm{m}}}{\mathrm{A} /\left(\mu_{\mathrm{m}}\right)}, \mathrm{I}_{\mathrm{m}}=\frac{\overline{\mathrm{I}}_{\mathrm{m}}}{\mathrm{N}_{\mathrm{m}}}=\frac{\overline{\mathrm{I}}_{\mathrm{m}}}{\mathrm{A} /\left(\mu_{\mathrm{m}}\right)}$

Since the total human and mosquito populations are constant, thus the time rate of change of human population equal to zero, i.e., $\frac{\mathrm{d} \overline{\mathbf{S}}_{\mathrm{h}}}{\mathrm{dt}}+\frac{\mathrm{d} \overline{\mathrm{I}}_{\mathrm{h}}}{\mathrm{dt}}+\frac{\mathrm{d} \overline{\mathbf{R}}_{\mathrm{h}}}{\mathrm{dt}}=0$. It means that the birth rate and the death rate of human population are equal, that is $\lambda_{\mathrm{h}}=\mu_{\mathrm{h}}$. The total number of Aedes mosquito at equilibrium equal to $\frac{\mathrm{A}}{\mu_{\mathrm{m}}}$.

Where:

$\mathrm{N}_{\mathrm{h}} \quad=$ The total human population

$\mathrm{N}_{\mathrm{m}} \quad=$ The total mosquito population

$\mathrm{S}_{\mathrm{h}}, \mathrm{I}_{\mathrm{h}}, \mathrm{R}_{\mathrm{h}}=$ The number of susceptible, infected, recovered human population, respectively

$\mathrm{S}_{\mathrm{m}}\left(\mathrm{I}_{\mathrm{m}}\right)=$ The number of susceptible (infected) mosquito population

$\lambda_{\mathrm{h}},\left(\mu_{\mathrm{h}}\right)=$ The birth (death) rate of human population

A $=$ The recruitment rate of mosquito population

$\mathrm{r}_{\mathrm{h}}(\mathrm{b})=$ The recovery (biting) rate of human population

$\gamma_{\mathrm{mh}}=$ The transmission rate of CHIKV from infected mosquito to human population:

$\gamma_{\mathrm{mh}}=\frac{\mathrm{b} \beta_{\mathrm{mh}}}{\mathrm{N}_{\mathrm{h}}}$

where, $\gamma_{\mathrm{mh}}$ is the transmission rate of CHIKV from infected human to mosquito population:

$\gamma_{\mathrm{hm}}=\frac{\mathrm{b} \beta_{\mathrm{hm}}}{\mathrm{N}_{\mathrm{h}}}$

where, $\mu_{\mathrm{m}}$ is the death rate of mosquito population.

And $\mathrm{p}$ is the efficacy of mosquito repellent for protecting the mosquito in human population. The reduced model is depicted as following:

$\frac{d S_{h}}{d t}=\mu_{h}(1-p)-\frac{b \beta_{m h}\left(A / \mu_{m}\right) S_{h} I_{m}}{N_{h}}-\mu_{h} S_{h}$

$\frac{d I_{h}}{d t}=\frac{b \beta_{m h}\left(A / \mu_{m}\right) S_{h} I_{m}}{N_{h}}-\left(r_{h}+\mu_{h}\right) I_{h}$ 
$\frac{d I_{m}}{d t}=b \beta_{h m}\left(1-I_{m}\right) I_{h}-\mu_{m} I_{m}$

\section{Analysis of the model:}

Equilibrium points: The model will be analyzed to investigate the equilibrium points and its stability. The system has two possible equilibrium points: the disease free equilibrium point and an endemic equilibrium point. Two equilibrium points are found by setting the RHS of Eq. 3-5 to zero. We obtained

Disease Free Equilibrium Point $\left(\mathbf{E}_{\mathbf{0}}\right)$ : In the absence of disease in the community, that is $\mathrm{I}_{\mathrm{h}}=0, \mathrm{I}_{\mathrm{m}}=0$. We obtained $S_{h}=1-p$, then $E_{0}=(1-p, 0,0)$.

Endemic Equilibrium Point $\left(\mathbf{E}_{1}\right)$ : In the other case when the disease is presented in the community, $\mathrm{I}_{\mathrm{h}}^{*} \neq 0, \mathrm{I}_{\mathrm{m}}^{*} \neq 0$, we obtained:

$I_{h}^{*}=\frac{(1-p) \mu_{h} M_{1}-\left(r_{h}+\mu_{h}\right) M_{2}}{\left(r_{h}+\mu_{h}\right)\left(1+M_{1}\right)}$

$\mathrm{I}_{\mathrm{m}}^{*}=\frac{\mathrm{I}_{\mathrm{h}}^{*}}{\mathrm{M}_{2}+\mathrm{I}_{\mathrm{h}}^{*}}$

$S_{h}^{*}=\frac{(1-p)\left(M_{2}+I_{h}^{*}\right)}{M_{2}+\left(1+M_{1}\right) I_{h}^{*}}$

With $\mathrm{M}_{1}=\frac{\mathrm{b} \beta_{\mathrm{mh}} \mathrm{A}}{\mu_{\mathrm{h}} \mu_{\mathrm{m}} \mathrm{N}_{\mathrm{h}}}$ and $\mathrm{M}_{2}=\frac{\mu_{\mathrm{m}}}{\mathrm{b} \beta_{\mathrm{hm}}}$

Thus, the endemic equilibrium point is $E_{1}\left(S_{h}^{*}, I_{h}^{*}, I_{m}^{*}\right)$.

Local asymptotical stability: The local stability of an equilibrium point is determined from the Jacobian matrix of the system of ordinary differential Eq. 3-5 evaluated at each equilibrium point. The Jacobian matrix at $\mathrm{E}_{0}$ is shown as:

$J_{0}=\left[\begin{array}{ccc}-\mu_{\mathrm{h}} & 0 & -\mathrm{M}_{1}(1-\mathrm{p}) \\ 0 & -\left(\mathrm{r}_{\mathrm{h}}+\mu_{\mathrm{h}}\right) & \mathrm{M}_{1}(1-\mathrm{p}) \\ 0 & \mathrm{~b} \beta_{\mathrm{hm}} & -\mu_{\mathrm{m}}\end{array}\right]$

The eigenvalues of the $\mathrm{J}_{0}$ are obtained by solving $\operatorname{det}\left(\mathrm{J}_{0}-\lambda \mathrm{I}\right)=0$. We obtained the characteristic equations:

$$
\left(\lambda+\mu_{\mathrm{h}}\right)\left(\lambda^{2}+\mathrm{A}_{1} \lambda+\mathrm{A}_{2}\right)=0
$$

Where:

$$
\begin{aligned}
& \mathrm{A}_{1}=\mathrm{r}_{\mathrm{h}}+\mu_{\mathrm{h}}+\mu_{\mathrm{m}}, \\
& \mathrm{A}_{2}=\mu_{\mathrm{m}}\left(\mathrm{r}_{\mathrm{h}}+\mu_{\mathrm{h}}\right)-\mathrm{b} \beta_{\mathrm{hm}} \mathrm{M}_{1}(1-\mathrm{p})
\end{aligned}
$$

From the characteristic Eq. 9, we get one of eigenvalue is $\lambda_{1}=-\mu_{\mathrm{h}}<0$. Next, to determine the other eigenvalues from the characteristic equation $\lambda^{2}+A_{1} \lambda+A_{2}=0$. The root of this equation is negative if it is satisfied with two conditions of Routh-Hurwitz criteria.

$\mathrm{E}_{0}$ is local asymptotically stable if $\lambda^{2}+\mathrm{A}_{1} \lambda+\mathrm{A}_{2}=0$ satisfies the following conditions:

1) $\mathrm{A}_{1}>0$

2) $\mathrm{A}_{2}>0$

To determine the stability of the equilibrium point $\left(E_{0}\right)$, we can see that $A_{1}$ is always positive and $A_{2}$ is positive when:

$\mathrm{b} \beta_{\mathrm{hm}} \mathrm{M}_{1}(1-\mathrm{p})<\mu_{\mathrm{m}}\left(\mathrm{r}_{\mathrm{h}}+\mu_{\mathrm{h}}\right)$

Moreover, we found that the disease free equilibrium point is locally asymptotically stable when $\mathrm{R}_{\mathrm{o}}<1$ where:

$\mathrm{R}_{0}=\frac{\mathrm{b} \beta_{\mathrm{hm}} \mathrm{M}_{1}(1-\mathrm{p})}{\mu_{\mathrm{m}}\left(\mathrm{r}_{\mathrm{h}}+\mu_{\mathrm{h}}\right)}$

Disease endemic equilibrium point: To determine the stability of the endemic equilibrium point, $E_{1}$, by finding the eigenvalues of Jacobian matrix at $\mathrm{E}_{1}$, as follow:

$J_{1}=\left[\begin{array}{ccc}-\mu_{\mathrm{h}}-\mathrm{M}_{1} \mathrm{I}_{\mathrm{m}}^{*} & 0 & -\mathrm{M}_{1} \mathrm{~S}_{\mathrm{h}}^{*} \\ -\mathrm{M}_{1} \mathrm{~S}_{\mathrm{h}}^{*} & -\mu_{\mathrm{h}}-\mathrm{M}_{1} \mathrm{I}_{\mathrm{m}}^{*} & -\mathrm{M}_{1} \mathrm{~S}_{\mathrm{h}}^{*} \\ 0 & \mathrm{~b} \beta_{\mathrm{hm}} & -\mathrm{b} \beta_{\mathrm{hm}} \mathrm{I}_{\mathrm{h}}^{*}-\mu_{\mathrm{m}}\end{array}\right]$

where, $\mathrm{S}_{\mathrm{h}}^{*}, \mathrm{I}_{\mathrm{h}}^{*}, \mathrm{I}_{\mathrm{m}}^{*}$ are given by Eq. 6-8. The characteristic equation of Jacobian matrix at $E_{1}$, given by Eq. 3-5, is:

$\lambda^{3}+B_{1} \lambda^{2}+B_{2} \lambda+B_{3}=0$

Where:

$$
\begin{aligned}
& \mathrm{B}_{1}=\mathrm{r}_{\mathrm{h}}+2 \mu_{\mathrm{h}}+\mu_{\mathrm{m}}+\mathrm{b} \beta_{\mathrm{hm}} \mathrm{I}_{\mathrm{m}}^{*}+\mathrm{M}_{1} \mathrm{I}_{\mathrm{m}}^{*}, \\
& \mathrm{~B}_{2}=\left(\mu_{\mathrm{m}}+\mathrm{b} \beta_{\mathrm{hm}} \mathrm{I}_{\mathrm{h}}^{*}\right)\left(2 \mu_{\mathrm{h}}+\mathrm{r}_{\mathrm{h}}+\mathrm{M}_{1} \mathrm{I}_{\mathrm{m}}^{*}\right)+ \\
& \left(\mu_{\mathrm{h}}+\mathrm{M}_{1} \mathrm{I}_{\mathrm{m}}^{*}\right)\left(\mathrm{r}_{\mathrm{h}}+\mu_{\mathrm{h}}\right)-\left(\mathrm{b} \beta_{\mathrm{hm}}\right)\left(\mathrm{M}_{1} \mathrm{~S}_{\mathrm{h}}^{*}\right), \\
& \mathrm{B}_{3}=\left(\mathrm{r}_{\mathrm{h}}+\mu_{\mathrm{h}}\right)\left(\mu_{\mathrm{h}}+\mathrm{M}_{1} \mathrm{I}_{\mathrm{m}}^{*}\right)\left(\mu_{\mathrm{m}}+\mathrm{b} \beta_{\mathrm{hm}} \mathrm{I}_{\mathrm{h}}^{*}\right)+ \\
& \left(\mathrm{M}_{2} \mathrm{~S}_{\mathrm{h}}^{*}+\mathrm{M}_{1} \mathrm{~b} \beta_{\mathrm{hm}} \mathrm{I}_{\mathrm{m}}^{*}\right)-\left(\mu_{\mathrm{h}}+\mathrm{M}_{1} \mathrm{I}_{\mathrm{m}}^{*}\right)\left(\mathrm{b} \beta_{\mathrm{hm}}\right)\left(\mathrm{M}_{1} \mathrm{~S}_{\mathrm{h}}^{*}\right),
\end{aligned}
$$


The three eigenvalues of $\lambda^{3}+B_{1} \lambda^{2}+B_{2} \lambda+B_{3}=0$ have negative real part if they satisfy the RouthHurwitz criteria. Thus, $\mathrm{E}_{1}$ is local asymptotically stable for $R_{0}>1$ if $\lambda^{3}+B_{1} \lambda^{2}+B_{2} \lambda+B_{3}=0$ satisfies the following conditions:
1) $B_{1}>0$;
2) $B_{3}>0$;
3) $\mathrm{B}_{1} \mathrm{~B}_{2}>\mathrm{B}_{3}$

\section{RESULTS}

Numerical results: In this study, we are interested in the transmission of Chikungunya fever with the effect of efficacy of mosquito repellent for protecting the mosquito. The parameters are obtained from the field study for some parameters such as $\mu_{\mathrm{h}}=1 /(65 \times 365)$ day $^{-1}$ corresponds to a life expectancy of 65 years in human, the recovery rate of human $r_{h}=1 / 7$ day $^{-1}$, which is corresponded to the recovery rate of human is 7 days, the mean life of mosquito $\mu_{\mathrm{m}}=1 / 7 \mathrm{day}^{-1}$, correspond to the expectancy of 7 days. Other parameters are arbitrarily chosen, such as the probability that CHIKV is transmitted to human is $\beta_{\mathrm{mh}}$ $=0.0005$ and the probability that CHIKV is transmitted to mosquito is $\beta_{\mathrm{hm}}=0.0002$ as shown in Table 1 .

Stability of disease free state: From the values of parameters listed in Table 1, we obtained the eigenvalues and basic reproductive number is:

$$
\begin{aligned}
& \lambda_{1}=-0.151962, \lambda_{2}=-0.133737, \\
& \lambda_{3}=-0.000042, R_{0}=0.004069<1
\end{aligned}
$$

Since all of these eigenvalues are to be negative and the basic reproductive number to be less than one, the equilibrium state will be the disease free state, $\mathrm{E}_{0}$ $(0.1,0,0)$ as shown in Fig. 2 (a) Susceptible human $\left(S_{h}\right)$ and (b) Infected human $\left(\mathrm{I}_{\mathrm{h}}\right)$, Infected mosquito $\left(\mathrm{I}_{\mathrm{m}}\right)$, proportion. The values of parameters are in the text. The solutions converge to the disease free equilibrium state as shown.

Stability of endemic state: Next we change the value of efficacy rate of the use of mosquito repellent for protecting in human population to be $\mathrm{p}=0.3$ and $\beta_{\mathrm{hm}}=$ $0.7, \beta_{\mathrm{mh}}=0.5$. The other values of parameters are listed in Table 1, we obtained the eigenvalues and basic reproductive number is:

$$
\begin{aligned}
& \lambda_{1}=-0.141205, \lambda_{2}=-0.724312, \\
& \lambda_{3}=-174655, \mathrm{R}_{0}=4.2005 \times 10^{12}>1
\end{aligned}
$$

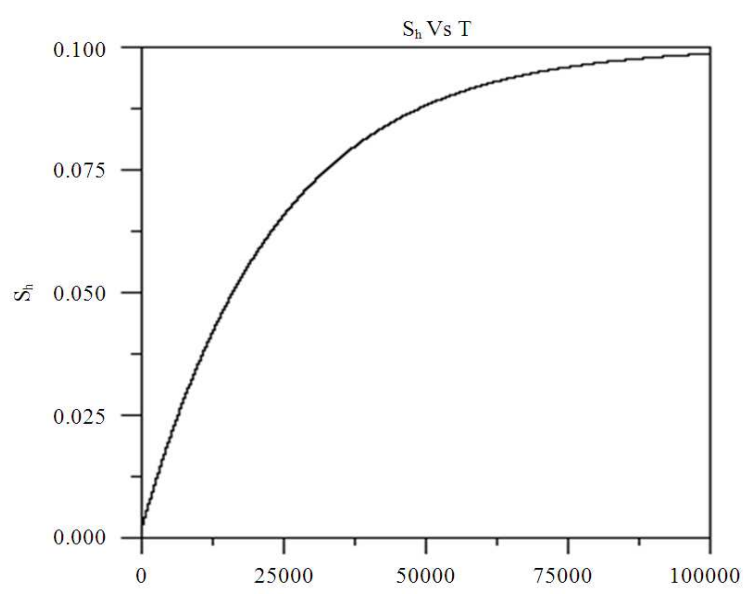

(a)

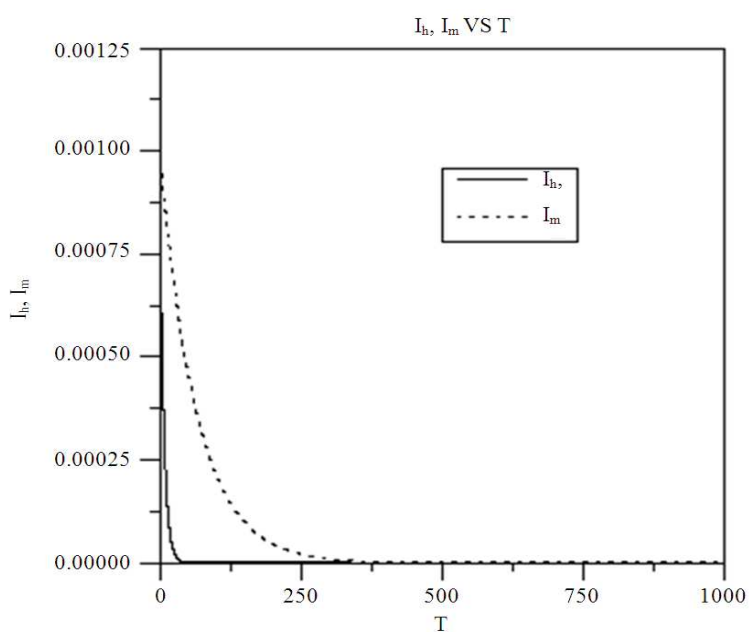

(b)

Fig. 2: Time series evolution of the population

\begin{tabular}{|c|c|c|}
\hline Parameters & Description & Values \\
\hline$\mu_{\mathrm{h}}$ & Birth (death) rate of human & $1 /(65 \times 365)$ day $^{-1}$ \\
\hline A & $\begin{array}{l}\text { Recruitment rate } \\
\text { of Aedes mosquito }\end{array}$ & 50000 \\
\hline$\beta_{\mathrm{mh}}$ & $\begin{array}{l}\text { Probability that } \\
\text { CHIKV transmit from } \\
\text { Aedes mosquito to human }\end{array}$ & 0.0005 \\
\hline$\beta_{\mathrm{hm}}$ & $\begin{array}{l}\text { Probability that CHIKV } \\
\text { transmit from human } \\
\text { to Aedes mosquito }\end{array}$ & 0.0002 \\
\hline $\mathrm{r}_{\mathrm{h}}$ & Recovery rate of human & $1 / 7$ day $^{-1}$ \\
\hline$\mu_{\mathrm{m}}$ & $\begin{array}{l}\text { Death rate of } \\
\text { Aedes mosquito }\end{array}$ & $1 / 7$ day $^{-1}$ \\
\hline $\mathrm{N}_{\mathrm{h}}$ & $\begin{array}{l}\text { Number of human } \\
\text { population }\end{array}$ & 1000000 \\
\hline $\mathrm{p}$ & $\begin{array}{l}\text { Efficacy rate of the use } \\
\text { of mosquito repellent for } \\
\text { protecting in human population }\end{array}$ & 0.9 \\
\hline
\end{tabular}
compartment $\mathrm{s}$ of the case at the disease free state

Table 1: Parameter values used in numerical simulations at Disease Free State 


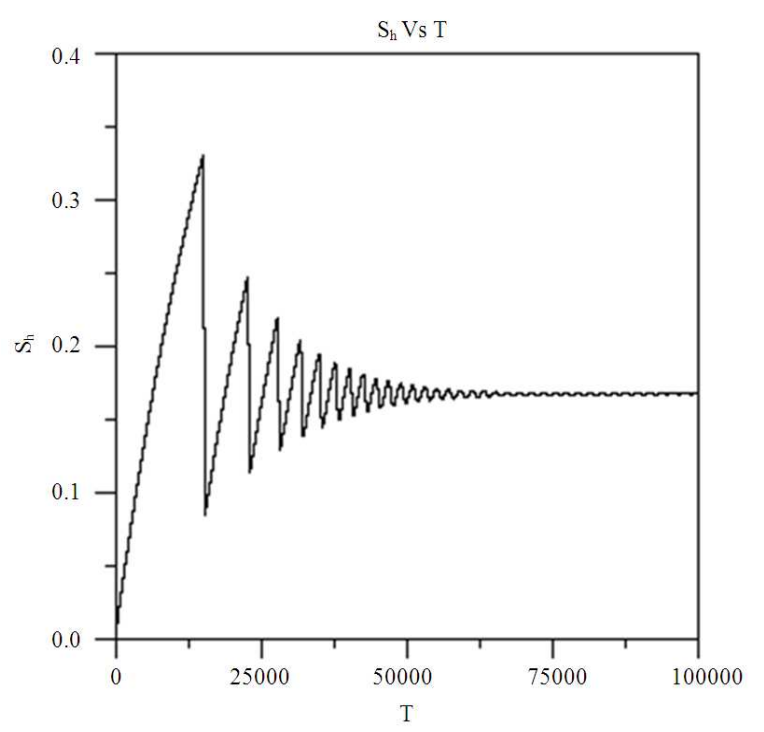

(a)

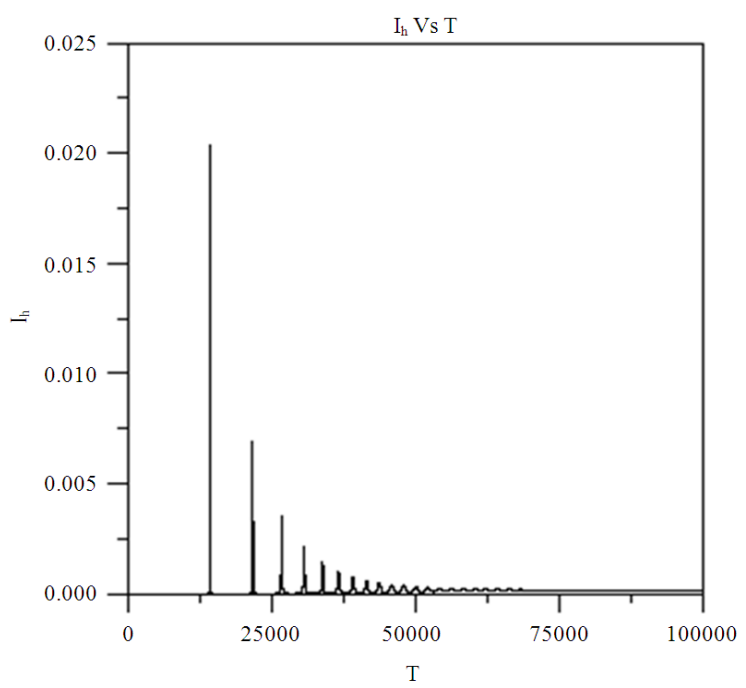

(b)

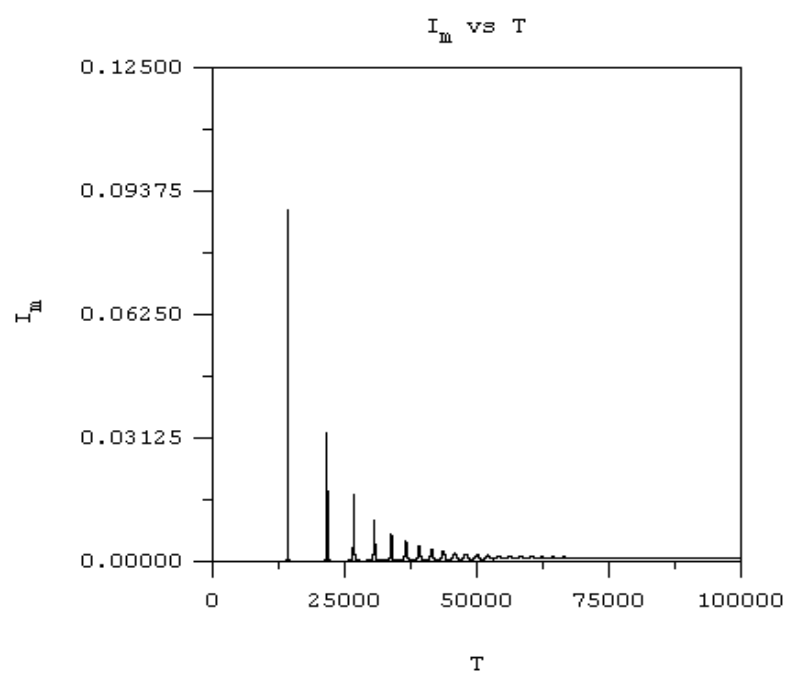

(c)

Fig. 3: Time series evolution of the population compartments of the case at the endemic state

Since all of these eigenvalues are to be negative and the basic reproductive number to be greater than one, the equilibrium state will be the endemic state, $E_{1}$ as shown in Fig. 3. (a) Susceptible human, (b) Infected human,(c) infected mosquito, proportion. The values of parameters are in the text, the solutions oscillate to the endemic equilibrium state.

In particular, we are interested in the numerical results when the value of efficacy rate of the use of mosquito repellent for protecting in human population by the different values of $\mathrm{p}=0.3, \mathrm{p}=0.4, \mathrm{p}=0.5, \mathrm{p}=$ 0.6 and $p=0.7$ when the other parameters are the same as using at endemic state. The number of infected humans was decreased as p increased as shown in Fig. 4.

\section{DISCUSSION}

We formulate the transmission model of Chikungunya by considering the effect of mosquito repellent to protect mosquito biting. The basic reproductive number is $\mathrm{R}_{0}=\sqrt{\mathrm{R}_{0}}$ where:

$$
\mathrm{R}_{0}=\frac{\mathrm{b} \beta_{\mathrm{hm}} \mathrm{M}_{1}(1-\mathrm{p})}{\mu_{\mathrm{m}}\left(\mathrm{r}_{\mathrm{h}}+\mu_{\mathrm{h}}\right)}
$$


Am. J. Applied Sci., 9 (4): 563-569, 2012

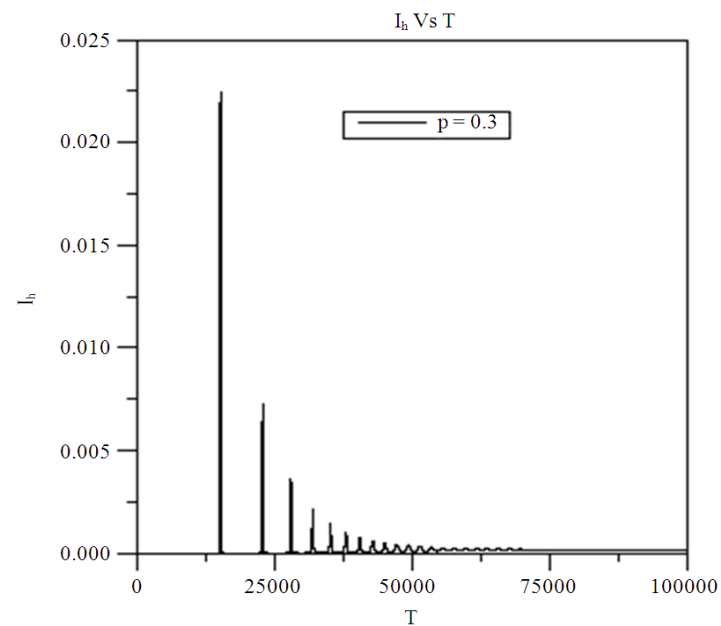

(a)

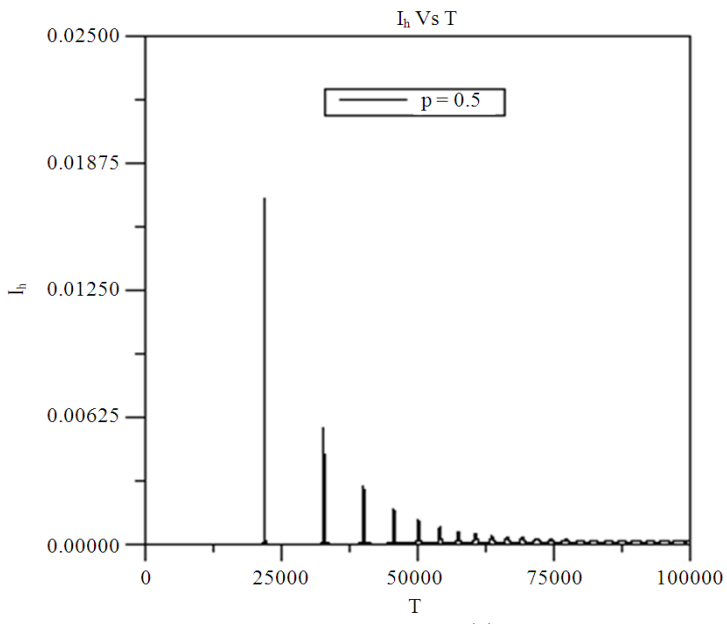

(c)

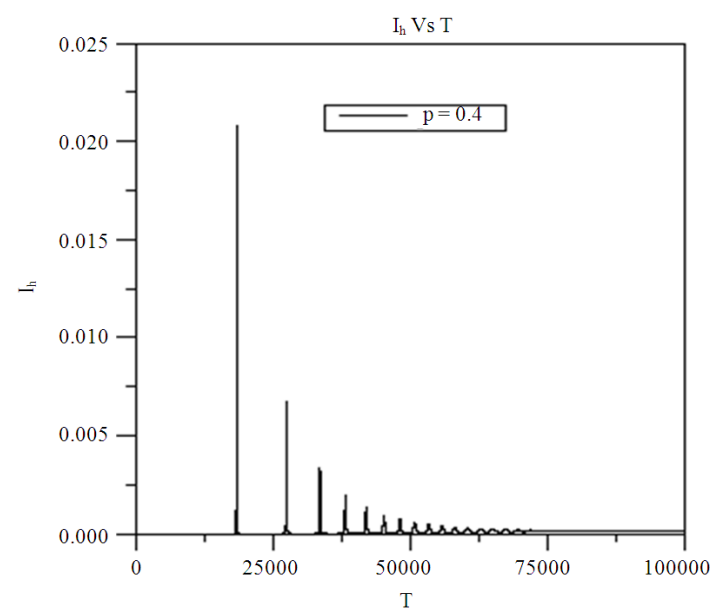

(b)

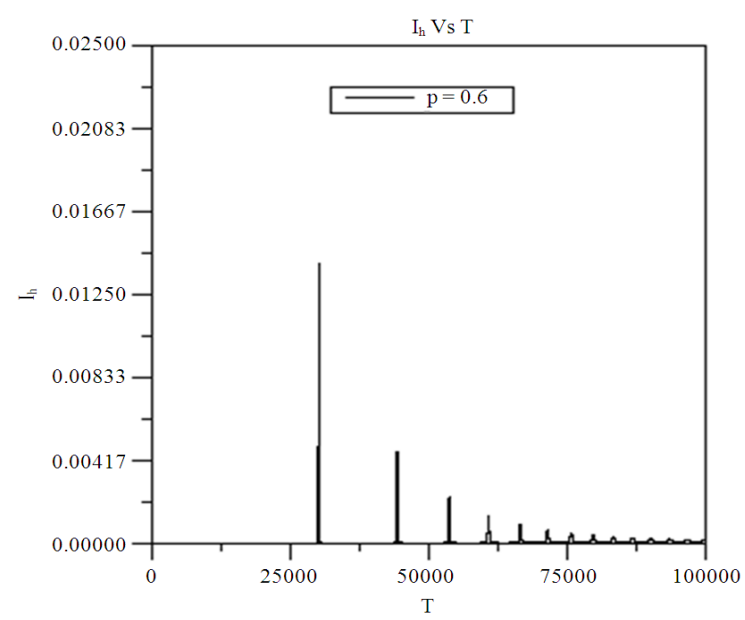

(d)

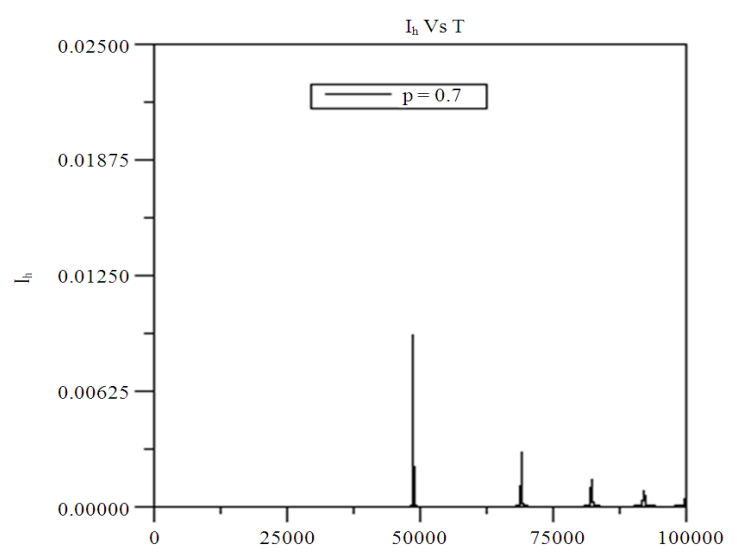

(e)

Fig. 4: Time series of infected human proportions. The values of parameters are the same as in endemic state with different value of $p$, (a) $p=0.3$, (b) $p=0.4$, (c) $p=0.5$, (d) $p=0.6$, (e) $p=0.7$. The number of infected humans was decreased as $\mathrm{p}$ increased 
$\mathrm{R}_{0}$ represent the number of secondary cases that arise when a single infective host is introduced into a susceptible host population through pathogen transmission by the vector (Anderson and May, 1992). $\mathrm{R}_{0}$ is the threshold condition and the stability of the solutions are shown in Fig. 2 and 3. For endemic state the value of $\mathrm{R}_{0}$ is very high due to human has low natural immunity with this strain of CHIKV, include the high mobility of human in the community and a genetic change at the position 226 in the gene for the glycoprotein E1/E2 created a mutated CHIKV strain which had an increased capability for replication in the Ae. albopictus (Tsetsarkin, 2009) and this mosquito is aggressive day time biter (30-46 times per hour), lives a long life (4-8 weeks)and has long flight radius (400-600 meters) (Pioloux et al., 2007).

\section{CONCLUSION}

We can conclusion that when the numbers of human which used the mosquito repellents increasing, it is decreasing the numbers of the susceptible human to receive the CHIKV. In Thailand, as Chikungunya fever has an epidemic. These alternative intervention could decreasing the numbers of infected human by campaign the outdoor workers using wisdom of community, that is, a mosquito repellent (Citrinella grass product) to protect themselves. Thus, the results of this study will the appropriate way to control the outbreak of this disease.

\section{ACKNOWLEDGEMENT}

Surapol Naowarat would like to thank Suratthani Rajabhat University for financial support according to Code:2554A1590213.

\section{REFERENCES}

Anderson, R.M. and R.M. May, 1992. Infectious Diseases of Humans: Dynamics and Control. 1st Edn., Oxford University Press, Oxford, ISBN: 019854040X, pp: 768.
Massad, E., S. Ma, M.N. Burattini, Y. Tun, F.A.B. Coutinho et al., 2008. The risk of chikungunya fever in a dengue-endemic area. J. Travel Med., 15: 147-155. DOI: 10.1111/j.1708-8305.2008.00186.x

Moulay, D., M.A. Aziz-Alaoui and M. Cadivel, 2011. The Chikungunya disease: Modeling, vector and transmission global dynamics. Math. Biosci., 229: 50-63. PMID: 21070789

Pioloux, G., B.A. Gauzere, S. Jaueguiberry and M. Strobel, 2007. Chikungunya, an epidemic arbovirosis. Lancet Infect. Dis., 7: 319-327. PMID: 17448935

Poletti, P., G. Messeri, M. Ajelli, R. Vallorani and C. Rizzo et al., 2011. Transmission potential of chikungunya virus and control measures: The case of Italy. PLoS ONE, 6: e18860-e18860. DOI: 10.1371/journal.pone.0018860

Thavara, U., A. Tawatsin, T. Pengsakul, P. Bhakdeenuan, S. Chanama et al., 2009. Outbreak of chikungunya fever in Thailand and virus detection in field population of vector mosquitoes, Aedes aegypti (L.) and Aedes albopictus Skuse (Diptera: Culicidae). Southeast Asian J. Trop. Med. Public Health, 40: 951-962. PMID: 19842379

Tilston, N., C. Skelly and P. Weinstein, 2009. PanEuropean Chikungunya surveillance: designing risk stratified surveillance zones. Int. J. Health Geographics, 8: 61-61. DOI: 10.1186/1476-072X8-61

Tsetsarkin, K.A., 2009. Adaptation of Chikungunya virus to Aedes albopictus mosquitoes: The role of mutations in the E1 and E2 glycoprotein. ProQuest, LLC.

Tsetsarkin, K.A., D.L. Vanlandingham, C.E. McGee and S. Higgs, 2007. A single mutation in chikungunya virus affects vector specificity and epidemic potential. PLos Pathog 3, e201- e201. PMID: 18069894 